\title{
Peer Review of "Finding Potential Adverse Events in the Unstructured Text of Electronic Health Care Records: Development of the Shakespeare Method"
}

\author{
Mark Antoniou, $\mathrm{PhD}$
}

The MARCS Institute for Brain, Behaviour and Development, Western Sydney University, Penrith, Australia

\section{Related Articles:}

Preprint (medRxiv): https://www.medrxiv.org/content/10.1101/2021.01.05.21249239v1

Preprint (JMIR Preprints): https://preprints.jmir.org/preprint/27017

Authors' Response to Peer-Review Reports: https://med.jmirx.org/2021/3/e31568/

Published Article: https://med.jmirx.org/2021/3/e27017/

(JMIRx Med 2021;2(3):e31550) doi: 10.2196/31550

This is a peer-review report submitted for the paper "Finding Potential Adverse Events in the Unstructured Text of Electronic Health Care Records: Development of the Shakespeare Method"

\section{Round 1 Review}

\section{General Comments}

This concise manuscript [1] reports an exploratory study that seeks to detect adverse events from the words within electronic health records. By conducting a computational linguistic analysis, the authors aimed to identify patterns of words that can be used to classify such events. The methodology is novel and has potential use cases that could benefit the automation and scalability of applications in the future.

I have some minor comments for the authors to consider:
1. At the end of the Introduction section, it would benefit the reader if the authors could provide some justification for why the Shakespeare method might be useful, rather than simply stating "We hoped."

2. The methods are well described and the results are straightforward.

3. In the Discussion section, there are some missing details that should be added. In particular, it would be useful for researchers seeking to follow up on this work to know what lessons were learned during the course of conducting this research. This could take the form of a short limitations paragraph, and importantly, some recommendations to guide future research. Relatedly, some additional details concerning how this work could inform real-world applications would also be welcome.

\section{Conflicts of Interest}

None declared.

\section{Reference}

1. Bright RA, Dowdy K, Rankin SK, Blok SV, Palmer LAM, Bright SJ. Finding Potential Adverse Events in the Unstructured Text of Electronic Health Care Records: Development of the Shakespeare Method. JMIRx Med 2021 Aug 11;2(3):e27017 [FREE Full text] [doi: 10.2196/27017]

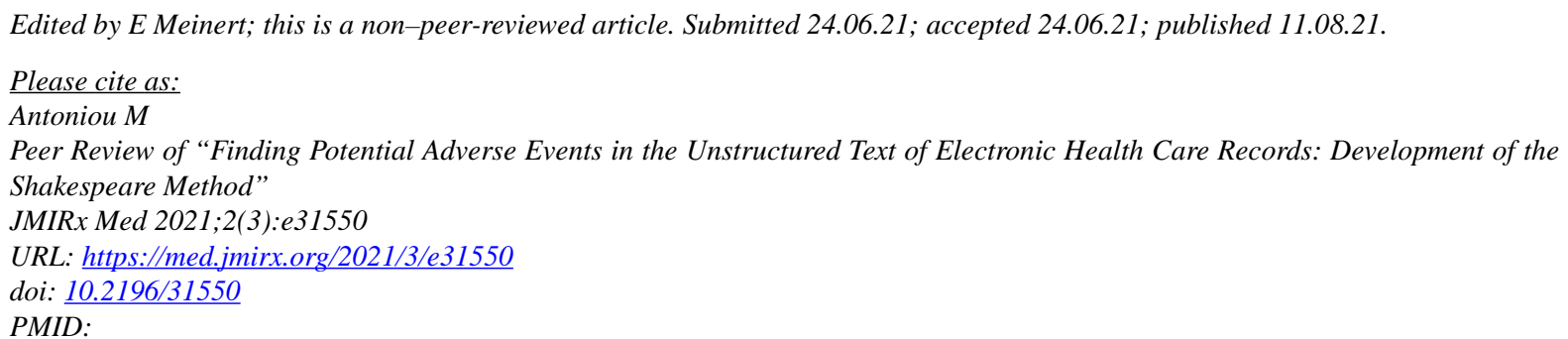


CMark Antoniou. Originally published in JMIRx Med (https://med.jmirx.org), 11.08.2021. This is an open-access article distributed under the terms of the Creative Commons Attribution License (https://creativecommons.org/licenses/by/4.0/), which permits unrestricted use, distribution, and reproduction in any medium, provided the original work, first published in JMIRx Med, is properly cited. The complete bibliographic information, a link to the original publication on https://med.jmirx.org/, as well as this copyright and license information must be included. 